\title{
SECAGEM DE FOLHAS DE EUCALIPTO (Corymbia citrodora) EM SECADOR TIPO CESTO ROTATIVO
}

\author{
J. V. de FREITAS, M. C. FERREIRA \\ Universidade Federal de São Carlos, Departamento de Engenharia Química \\ E-mail para contato: mariaf@ufscar.br
}

\begin{abstract}
RESUMO - As folhas da espécie de eucalipto (Corymbia citriodora) são grandes produtoras de óleos essenciais e a secagem permite que elas sejam armazenadas por períodos longos. O objetivo deste trabalho é avaliar a secagem de folhas de eucalipto em um secador tipo cesto rotativo, que está sendo desenvolvido no Centro de Secagem do DEQ-UFSCar. O secador consiste de um cilindro construído de tela metálica perfurada, acoplado a um motor que permite a sua rotação em torno do eixo horizontal. $\mathrm{O}$ ar fornecido por um soprador é aquecido e alimentado através das paredes laterais do cilindro, no sentido perpendicular ao seu eixo. Foi avaliada a influência da temperatura do ar $\left(50\right.$ e $\left.70^{\circ} \mathrm{C}\right)$ e da carga de material (50 e 100 gramas) na redução de umidade. Foram avaliadas a alteração de cor e da densidade bulk das folhas provocada pela secagem. Os testes de secagem indicaram que a temperatura é a variável de maior influência na retirada de umidade, e que o tempo de secagem foi o fator de maior influência sobre a alteração da cor.
\end{abstract}

\section{INTRODUÇÃO}

A espécie Corymbia citriodora tem origem na Austrália e foi introduzida no Brasil com outras espécies de eucalipto, inicialmente para a produção de madeira. É uma árvore de porte médio, que ocorre em vários tipos de solo, em florestas abertas com presença de outras espécies, sendo facilmente identificada pelo cheiro do citronelal de suas folhas. É amplamente cultivada no Brasil para a produção de madeira e uma das espécies mais exploradas para a produção de óleos essenciais. Estes são extraídos das folhas, muito utilizados em indústria de perfumaria, principalmente nos produtos de limpeza (Vitti; Brito, 2003).

A secagem das plantas consiste na remoção de parte de água contida no produto a um nível de umidade adequado para armazenamento (Martinazzo, 2006). A umidade pós-colheita de plantas acelera a ação enzimática e o desenvolvimento de fungos e microorganismos e a secagem contribui para reduzir estes processos, permitindo a conservação das propriedades físicas e químicas dos materiais por períodos mais longos (Mochi, 2005).

Um dos problemas observados na secagem convectiva de folhas em secadores de esteira ou de bandejas, nos quais camadas de leito fixo do material são colocados em contato com o ar, é a formação de gradientes de umidade e temperatura, que resultam em uma secagem heterogênea e 
em produtos com distribuição de umidade não-uniforme, inadequados para armazenamento. Na secagem de folhas em estufa, este problema é usualmente minimizado revolvendo-se manualmente o material. Lima (2013) constatou que o uso de vibração vertical na secagem convectiva de leitos fixos de folhas de manjericão foi uma técnica eficiente para garantir uma secagem homogênea das folhas. Estas constatações levaram à proposta de desenvolvimento de um secador para folhas, com configuração que permita uma boa movimentação do material em seu interior e um contato uniforme destas com o ar de secagem. O secador, denominado cesto rotativo, encontra-se em fase de desenvolvimento, e consiste basicamente de um cilindro rotativo com paredes laterais perfuradas, através das quais é alimentado o ar aquecido para secagem.

O objetivo deste trabalho é avaliar o desempenho do secador tipo cesto rotativo na secagem de folhas de Corymbia citriodora, e investigar os efeitos da temperatura do ar e carga do material na cinética de secagem. Avaliou-se ainda a variação da cor e da densidade bulk do material devido ao processo de secagem.

\section{MATERIAIS E MÉTODOS}

O secador tipo cesto rotativo consiste de um cilindro, com $20 \mathrm{~cm}$ de diâmetro e $18 \mathrm{~cm}$ de comprimento, construído em tela metálica perfurada e acoplado a um motor que permite a rotação em torno do eixo horizontal. Este cesto está acoplado à saída de uma tubulação tipo túnel, com 20 $\mathrm{cm}$ de largura por $20 \mathrm{~cm}$ de altura, através da qual escoa o ar fornecido por um soprador da marca Ibram (modelo VC 3560, 3469 rpm, 4 CV). A Figura 1(a) mostra um corte frontal e a Figura 1(b) o cesto acoplado no duto de alimentação de ar. O aquecimento do ar é feito por um conjunto de resistências elétricas ligados em um variac Varivolt, que permite variar a potência de saída e assim, possibilita o controle da temperatura. $\mathrm{O}$ ar aquecido escoa, portanto, através da parede lateral do cilindro, que gira a uma velocidade constante, possibilitando a movimentação do material no seu interior.

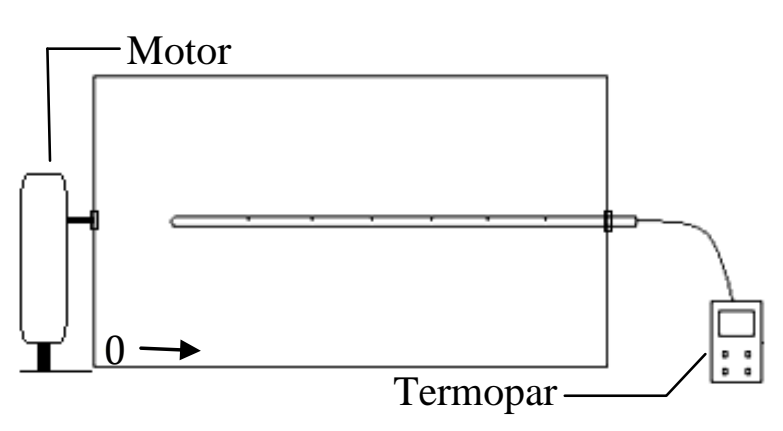

(a)

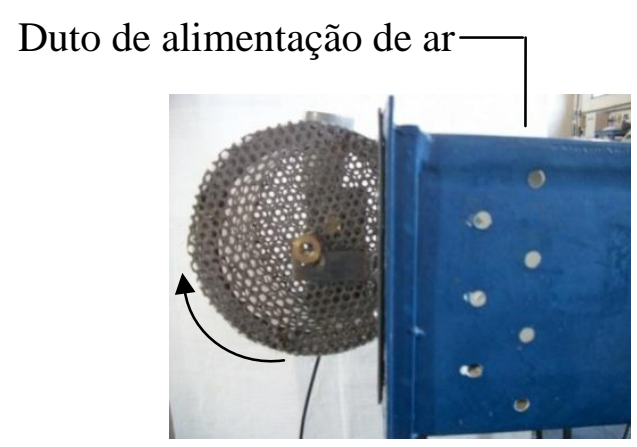

(b)

Figura 1: Cilindro em vista frontal (a) e alimentação do ar quente em vista lateral do secador (b)

São diversas as variáveis que podem influenciar a secagem neste secador: temperatura do ar, velocidade do ar, rotação do cilindro e carga de folhas no cilindro. Nesta etapa do trabalho, optouse por fixar a velocidade do ar $(0,75 \mathrm{~m} / \mathrm{s})$ e a rotação do cilindro $(4 \mathrm{rpm})$ e foram variadas a 
temperatura do $\operatorname{ar}\left(50\right.$ e $\left.70^{\circ} \mathrm{C}\right)$ e a massa de folhas $(50$ e $100 \mathrm{~g})$.

Durante os testes, a temperatura do ar no interior do cilindro foi medida ao longo da posição axial com um termopar Digi-Sense Cole Parmer. As medidas das temperaturas foram feitas no eixo central do cilindro, em 5 posições axiais a partir da base, a cada $3 \mathrm{~cm}$, de acordo com o diagrama indicado na Figura 1(a). Não foi possível medir a velocidade do ar no interior do cilindro em movimento na presença das folhas, uma vez que as oscilações locais impediram a leitura de valores estáveis com a sonda disponível.

A secagem das folhas foi efetuada até se atingir a massa constante. Em intervalos de tempo, o material era coletado e pesado em balança semi-analítica Gehaka (BK 400, precisão de 0,001 g). Com os dados de massa em função do tempo foi calculada a umidade adimensional (MR) utilizando a Equação 1. Em seguida, foram construídos os gráficos da umidade adimensional em função do tempo de secagem.

$$
M R=\frac{X_{t}-X_{e q}}{X_{i}-X_{e q}}
$$

onde $\mathrm{X}$ corresponde ao conteúdo de umidade (b.s.) e o subscrito t corresponde ao instante $\mathrm{t}$, i à umidade inicial e eq à umidade de equilíbrio dinâmico, obtida no final da secagem.

As folhas de eucalipto (Corymbia citriodora) foram colhidas no Cerrado da Universidade Federal de São Carlos. Foram tiradas dos galhos e separadas por tamanho, descartando as folhas menores que $10 \mathrm{~cm}$.

A determinação do conteúdo de umidade inicial $\left(\mathrm{U}_{\mathrm{bu}}\right)$ para as folhas in natura, foi feito em estufa à vácuo Tecnal (TE-395) à $70^{\circ} \mathrm{C}$, pelo método gravimétrico, utilizando a Equação 2:

$$
U_{b u}=\frac{M_{H 2 O}}{M_{H 2 O}+M_{S}}
$$

$\mathrm{M}_{\mathrm{H} 2 \mathrm{O}}$ é a massa de água $(\mathrm{g})$ e $\mathrm{M}_{\mathrm{S}}$ é a massa de folhas secas $(\mathrm{g})$

A densidade bulk $\left(\rho_{\mathrm{b}}\right)$ é a razão da massa de partículas $\left(\mathrm{M}_{\mathrm{p}}\right)$ e o volume do leito $\left(\mathrm{V}_{\mathrm{p}}\right)$. Esta propriedade foi determinada para as folhas in-natura e após a secagem, sendo 4 amostras para cada uma, medindo-se o volume ocupado por uma massa conhecida de folhas, e calculada segundo a Equação 3:

$$
\rho_{b}=\frac{M_{p}}{V_{p}}
$$

No procedimento de determinação da cor, foram retiradas 3 amostras do conjunto de cada tratamento, para a leitura no espectrofotômetro. A cor foi quantificada pela leitura de refletância das coordenadas L*, a* e b em um espectrofotômetro Konica Minolta (CM-5), empregando o sistema Cielab, no qual a* varia entre o verde $\left(-a^{*}\right)$ e o vermelho $\left(+a^{*}\right), b^{*}$ entre o azul $\left(-b^{*}\right)$ e o 
amarelo $\left(+b^{*}\right)$ e $L^{*}$ é a luminosidade que varia entre $0 \%$ - negro e $100 \%$ - branco. A variação de cor $(\Delta \mathrm{E})$ foi estimada a partir da Equação 4:

$$
\Delta E=\sqrt{\left(L_{f}^{*}-L_{i}^{*}\right)^{2}+\left(a_{f}^{*}-a_{i}^{*}\right)^{2}+\left(b_{f}^{*}-b_{i}^{*}\right)^{2}}
$$

Os subscritos i e f representam os valores do início e final do experimento, respectivamente.

\section{RESULTADOS}

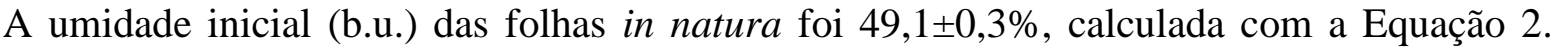
Este valor está de acordo com os valores encontrados no trabalho de Castro et al (2008), em que o conteúdo de umidade (b.u.) para as folhas de Corymbia citriodora variam de 44 à $60 \%$. Nas Figuras 2(a) e 2(b) estão apresentadas as curvas de MR em função do tempo na secagem de folhas para as temperaturas de $50^{\circ} \mathrm{C}$ e $70^{\circ} \mathrm{C}$, parametrizadas na massa de folhas.

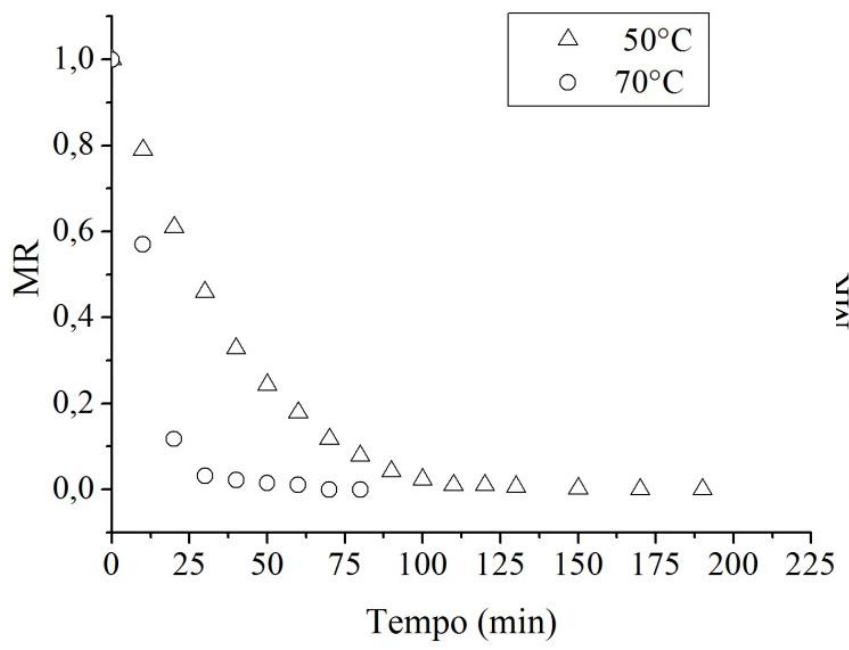

(a)

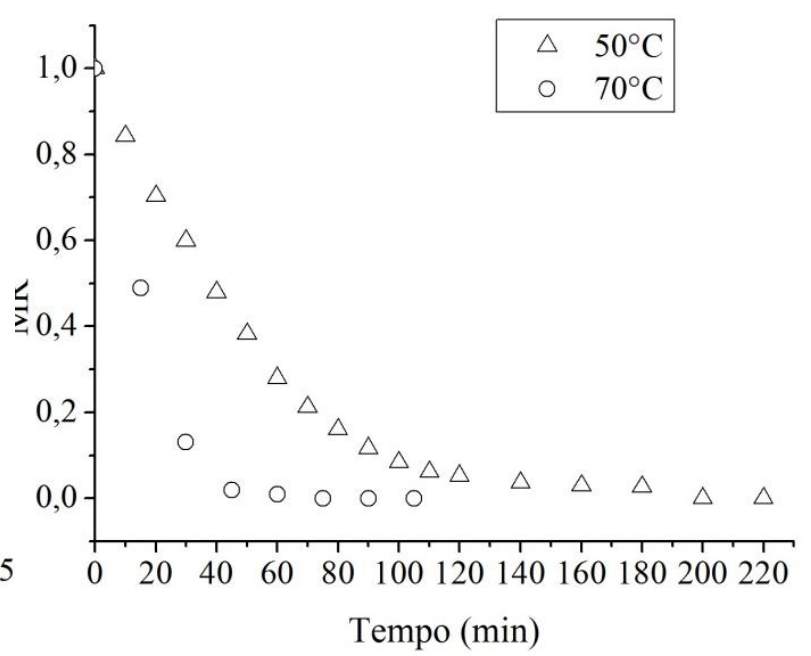

(b)

Figura 2: MR em função do tempo para 50(a) e 100(b) gramas de folhas

Nota-se que a temperatura influenciou fortemente a retirada de umidade e de forma significativa na diminuição do tempo de secagem. Para $100 \mathrm{~g}$ de folhas, em $70^{\circ} \mathrm{C}$, a redução no tempo de secagem é aproximadamente $53 \%$ em relação à temperatura de $50^{\circ} \mathrm{C}$. Nos primeiros 30 minutos de secagem a $70^{\circ} \mathrm{C}$, a umidade adimensional caiu para um valor de 0,13 , que corresponde à retirada de $97 \%$ da umidade. Para a massa de $50 \mathrm{~g}$ de folhas, a redução do tempo de secagem foi de $58 \%$ com o aumento de temperatura de 50 para $70^{\circ} \mathrm{C}$. Comportamento similar foi relatado no trabalho de Mochi (2005), na secagem de folhas de Eucalyptus camaldulensis em leito fixo, utilizando temperaturas de 35 a $70^{\circ} \mathrm{C}$, com velocidade de $0,6 \mathrm{~m} / \mathrm{s}$. A autora verificou que a maior parte da umidade foi retirada após 30 minutos de secagem para temperaturas superiores a $50^{\circ} \mathrm{C}$ 
Na Figura 3 são apresentadas as curvas de secagem para as massas de 50 e $100 \mathrm{~g}$ de material.

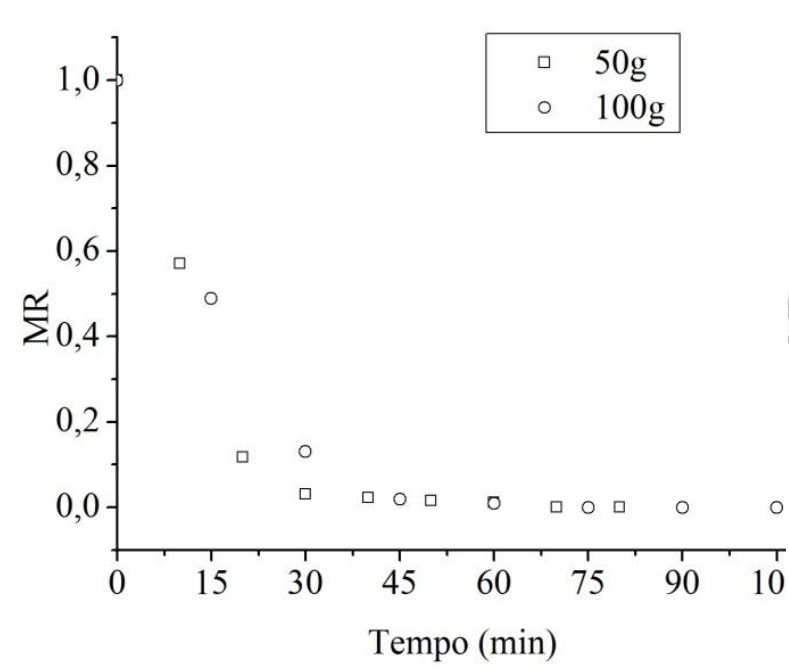

(a)

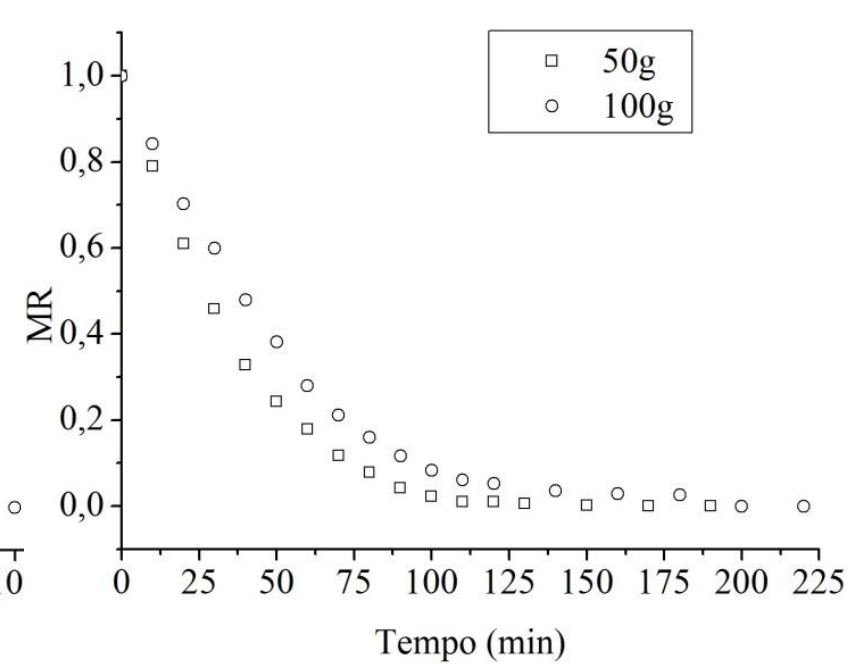

(b)

Figura 3: MR em função do tempo para $70{ }^{\circ} \mathrm{C}$ (a) e $50^{\circ} \mathrm{C}$ (b)

Observa-se que para as 2 temperaturas utilizadas as curvas de secagem foram afetadas pela massa de folhas inseridas no secador e que as taxas de secagem são maiores para a menor massa. Os tempos de secagem para as temperaturas de $70^{\circ} \mathrm{C}$ e $50^{\circ} \mathrm{C}$ foram reduzidos em aproximadamente 24 e $14 \%$ respectivamente, com a redução da massa no secador de $100 \mathrm{~g}$ para $50 \mathrm{~g}$. Esta redução no tempo de secagem a uma dada temperatura, indica que o contato do ar com as folhas foi mais efetivo para a menor massa.

A configuração do secador foi proposta visando uma boa mistura do material e bom contato entre as folhas e o ar. Durante a secagem das folhas de eucalipto, observou-se que com a retirada da umidade as folhas ficam rígidas e retorcidas, mas não encolhem, diferentemente do comportamento relatado por Lima (2013) na secagem de folhas de manjericão, que encolhem consideravelmente. Observou-se durante os ensaios que esta característica das folhas de eucalipto dificultava a movimentação das folhas no interior do secador e que, mesmo com a rotação do cesto, o conjunto de folhas formava praticamente um leito fixo. Isto ocorreu em todas as condições investigadas. A massa de material influi no empacotamento e porosidade do leito fixo formado. Uma menor quantidade de folhas resulta em um leito fixo com maior porosidade média e maior permeabilidade, consequentemente, é esperada uma melhora no contato entre o ar e o material, o que favorece o aumento das taxas de secagem. Ainda são necessárias mais investigações para avaliar qual a massa mais indicada para operação neste secador.

Na Figura 4 são mostradas as curvas para todas as condições investigadas. Comparando as 2 variáveis avaliadas na secagem de folhas, observa-se que a temperatura teve maior influência no processo de secagem do que a massa de folhas, e que a $70{ }^{\circ} \mathrm{C}$ a influência da massa foi menor 
do que a $50^{\circ} \mathrm{C}$. Isto porque o maior potencial térmico na temperatura mais alta acaba compensando o efeito negativo do aumento de massa.

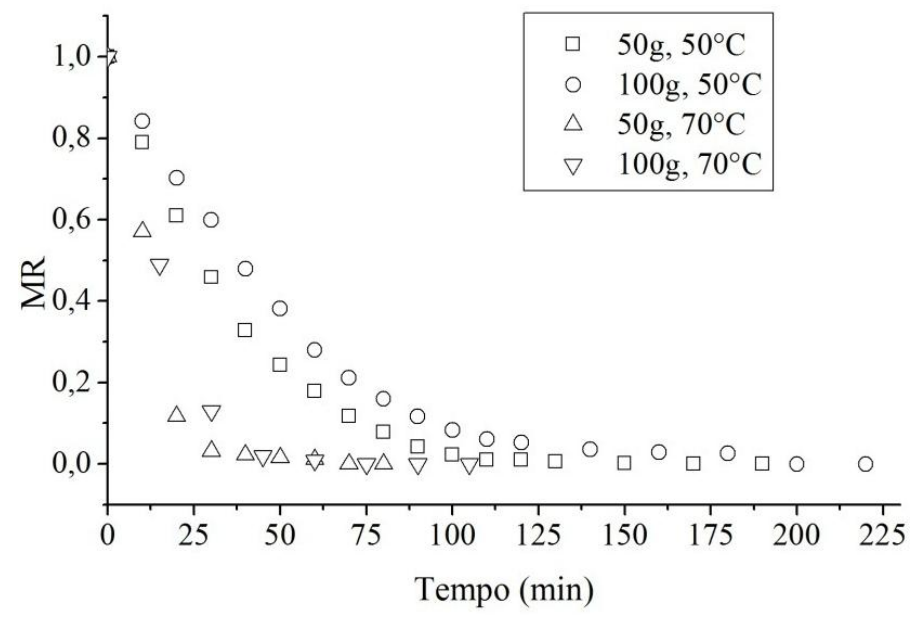

Figura 4: MR em função do tempo para todos os tratamentos de secagem

Durante os ensaios de secagem, foi medida a temperatura do ar em diferentes posições axiais no interior do cilindro, para verificar a sua uniformidade. Os resultados para a secagem de $100 \mathrm{~g}$ de folhas são mostrados nas Figuras 5(a) e 5(b). Os dados para secagem de $50 \mathrm{~g}$ foram similares, por isto não serão apresentados.

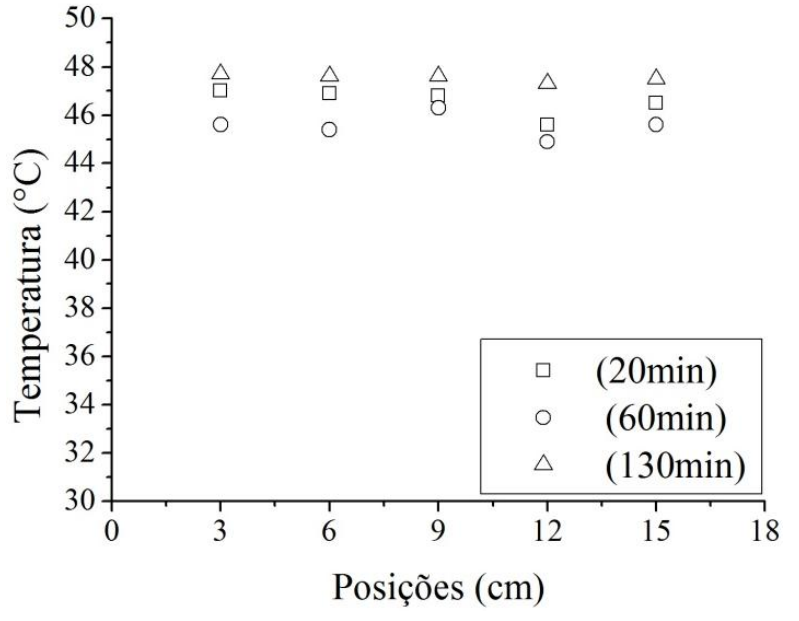

(a)

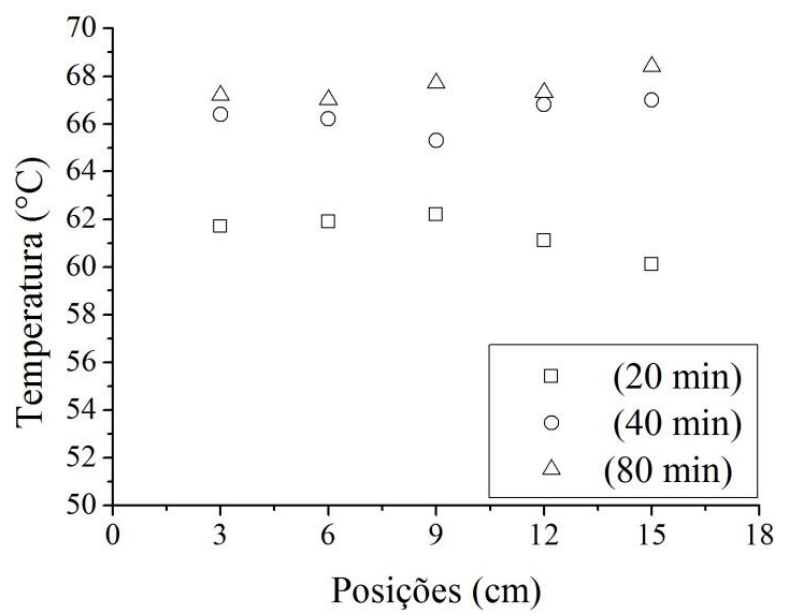

(b)

Figura 5: Temperaturas do ar no interior do cilindro em funcão da posição axial durante a secagem nas temperaturas de $50^{\circ} \mathrm{C}$ (a) e $70^{\circ} \mathrm{C}$ (b), para $100 \mathrm{~g}$ de folhas

Observa-se que a temperatura variou pouco ao longo do eixo do cilindro, com diferenças máximas de até $2^{\circ} \mathrm{C}$ na secagem com ar alimentado a $50^{\circ} \mathrm{C}$ e até $3^{\circ} \mathrm{C}$ na secagem a $70^{\circ} \mathrm{C}$, 
indicando uniformidade da temperatura. Na configuração atual, não foi possível obter dados da variação da temperatura do ar com a posição radial. Observações visuais do material seco mostraram que as condições utilizadas proporcionaram secagem uniforme, apesar de não ter sido alcançada uma boa movimentação das folhas no interior do cesto. O movimento de rotação do cesto provavelmente contribui para a homogeneidade da secagem, pois permite que o ar entre em contato com diferentes porções do material, minimizando gradientes de umidade e temperatura.

Os valores da densidade bulk obtidos foram $0,14 \pm 0,02 \mathrm{~g} / \mathrm{cm}^{3}$ para as folhas in-natura e $0,020 \pm 0,001 \mathrm{~g} / \mathrm{cm}^{3}$, para as folhas secas. Estes valores fornecem estimativas aproximadas, já que não foram obtidos de forma totalmente padronizada e baseiam-se em poucas repetições. Eles fornecem, contudo, uma estimativa razoável da variação sofrida durante o processo. Nota-se uma grande diminuição da densidade bulk das folhas secas, que é apenas $15 \%$ do valor da densidade das folhas in-natura. Como as folhas de eucalipto não encolhem durante a secagem, o volume ocupado pelo conjunto no secador aumentava consideravelmente, apesar da redução de umidade, o que contribuiu para a dificuldade de movimentação das mesmas no interior do cesto, como mencionado anteriormente. Assumindo que os 'pacotes' são similares e que os valores de densidades bulk medidos fornecem estimativas razoáveis da densidade bulk das folhas no interior do cesto, estimou-se a expansão de volume durante a secagem. O volume inicialmente ocupado por $100 \mathrm{~g}$ de folhas in-natura, com base na densidade medida, é igual a $714 \mathrm{~cm}^{3}$, o que corresponde a cerca de $13 \%$ do volume do cesto. A massa seca resultante após a secagem é de 51 $\mathrm{g}$, e nesta condição o volume ocupado aumenta para $2250 \mathrm{~cm}^{3}$, que corresponde a cerca de $40 \%$ do volume do cesto. Assim, ao final da secagem, o volume ocupado pelas folhas é cerca de 3 vezes superior ao volume inicial. Na secagem de folhas de manjericão em leito fixo Lima (2013) observou também uma grande redução na densidade bulk $\left(0,089 \mathrm{~g} / \mathrm{cm}^{3}\right.$ para as folhas in-natura e $0,018 \mathrm{~g} / \mathrm{cm}^{3}$ para as folhas secas). As folhas de manjericão in-natura, entretanto, possuem umidade muito superior à das folhas de eucalipto (em média $86 \%$ em b.u.) e encolhem durante a secagem, desta forma na secagem de manjericão, o volume final do conjunto de folhas secas era muito inferior ao inicial (Lima, 2013). De acordo com Bicalho et al (2010) para secadores de tambor rotativos com cascateamento, a fração de sólidos dentro do tambor deve ser de 10 a $15 \%$ do seu volume. Os resultados obtidos aqui mostram que na secagem de folhas de eucalipto no secador de cesto rotativo, para uma condição ótima de operação as frações devem ser ainda menores.

A Figura 6 mostra a variação de cor das folhas secas em relação às folhas in natura. Notase que houve diferença nas médias das variações da cor entre as temperaturas de 50 e $70^{\circ} \mathrm{C}$, sendo que para a temperatura de $50^{\circ} \mathrm{C}$ a variação de cor foi maior. A temperatura é um fator conhecido na degradação da cor (Gasparin, 2012), contudo neste caso, o tempo de secagem para $50^{\circ} \mathrm{C}$ foi muito superior do que a $70^{\circ} \mathrm{C}$, assim as folhas ficaram expostas ao ar aquecido por tempos muito maiores. Isto possivelmente justifica a maior alteração de cor observada para as folhas na secagem a $50^{\circ} \mathrm{C}$. 


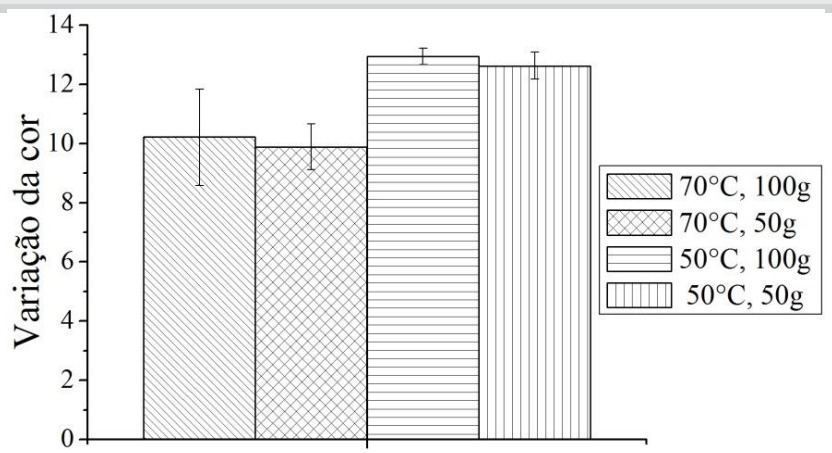

Figura 6: Variação da cor $(\Delta \mathrm{E})$ das folhas para todos os tratamentos de secagem

\section{CONCLUSÕES}

Os resultados permitem concluir que o secador de cesto rotativo permitiu a secagem uniforme das folhas de eucalipto, e que a temperatura foi a variável que mais influenciou a secagem. A secagem proporcionou uma redução expressiva, de cerca de 7 vezes, na densidade bulk do conjunto das folhas. Em relação à variação de cor, na faixa de temperaturas investigadas, o tempo de contato com o ar aquecido foi o fator predominante nas alterações. Este estudo ainda é preliminar, e investigações adicionais ainda são necessárias para avaliar o efeito de outras variáveis (como velocidade do ar e velocidade de rotação do cesto) na secagem e também para determinar condições ótimas para operação.

\section{REFERÊNCIAS}

BICALHO, I. C.; DUARTE, C. R.; SILVÉRIO, B. C.; BARROZO, M. A. S. Estudo experimental e de simulação da fluidodinâmica em secadores rotatórios com cascateamento. FEQ-UFU, Uberlândia, 2010.

CASTRO, N. E. A.; CARVAlhO, G. J.; CARDOSO M. G.; PIMENTEL, F. A.; CORREA, R. M.; GUIMARÃES, L. G. L. Avaliação de rendimento e dos constituintes químicos do óleo essencial de folhas de E. Citriodora Hook colhidas em diferentes épocas do ano em municípios de Minas Gerais. Revista Brasileira de Plantas Medicinais. v. 10, n. 1, p. 70-75, 2008.

GASPARIN, P. P. Secagem de Mentha piperita em leito fixo utilizando diferentes temperaturas e velocidades de ar. 82 f. Dissertação (Mestrado) - Curso de Engenharia Agrícola, UNIOESTE, Cascavel-PR, 2012.

LIMA, Renata Aquino de Brito. Análise da secagem convectiva de folhas de manjericão. $169 \mathrm{f}$. Tese (Doutorado), PPG-EQ, UFSCar, São Carlos, 2013.

MARTINAZZO, A. P. Secagem, armazenamento e qualidade das folhas de Cymbopogon citratus (D. C.) Stapf. 156 f. Dissertação (Mestrado) - Curso de Engenharia Agrícola, UFV, Viçosa, 2006.

MOCHI, V. T. Efeito da temperatura de secagem no rendimento do óleo essencial e teor de 1, 8cineol presentes nas folhas de Eucalyptus camaldulensis. 91 f. Dissertação (Mestrado) PPG-EQ, UNICAMP, Campinas, 2005.

VITTI, A. M. S.; BRITO, J. O. Óleo essencial de eucalipto. Documentos Florestais, n. 17, 2003. 